\title{
Almost and Its Kin, Across Categories
}

\author{
Marcin Morzycki \\ University of Massachusetts Amherst
}

In some respects, almost appears to be not one modifier but two. One incarnation of almost is a verbal modifier:

(1) Clyde almost killed Floyd.

This almost gives rise to a variety of readings that have been taken as evidence for lexical decomposition of verbs (Morgan 1969, McCawley 1972, Rapp and Stechow 1999). In another incarnation, almost is a nominal modifier:

(2) Almost every chiropractor plays the ukulele.

This incarnation imposes a restriction on quantifiers that has made it useful as a diagnostic for universal quantification (Carlson 1981, Kadmon and Landman 1993). It is apparently not usual to consider these forms of almost together. Indeed, one might suppose that these are two entirely distinct modifiers that happen to be homophonous, simply by chance.

But this cannot be the case. If it were indeed some accident of the lexicon that almost manifests these two apparently divergent sets of syntactic and semantic characteristics, it should be unique, or nearly so, in this respect. Yet in fact, almost shares all of its essential characteristics with a natural class of modifiers - henceforth 'almost modifiers' - of which it is one quite unexceptional member. Among its kin in this class are virtually, nearly, damn near, pretty much, not quite, and just about (though not bare about). All the modifiers of this class occur in the same positions, give rise to the same range of readings, and impose similar restrictions on the expressions they modify. Moreover, the restrictions they impose on different categories are intuitively similar to each other. Thus, because almost shares its properties with a significantly larger class of expressions, its behavior in the nominal and verbal domains can be no accident, but rather must reflect a more general puzzle.

The aim here is to elucidate that puzzle and suggest an approach to solving it. The essential distinguishing properties of the almost class are examined in section 1. Several possible approaches to the problem are considered in section 2. Then, in section 3, an analysis of almost modifiers in terms of intensional similarity is pursued that may be extended across categories. The remaining steps toward an account of this cross-categoriality are taken in section 4, which proposes a division of semantic labor between almost modifiers themselves and a syntactic feature in functional structure that licenses them. Section 5 concludes. 


\section{Some Data: Distribution and Selectional Restrictions}

\subsection{Distribution: Cross-Categorial and Left Peripheral}

Almost modifiers occur in (the extended projections of) DP, VP, AP, PP, and AdvP, always on the extreme left periphery: ${ }^{1}$
a. [Almost/nearly/practically every chiropractor] plays the ukulele.
b. Tilden [almost/nearly/practically won].
c. The soup is [almost/nearly/practically free of insects].
d. Floyd sailed [almost/nearly/practically around the world].
e. The candidate behaved [almost/nearly/practically inexcusably].

For each of these categories, the left edge is the only possible location an almost modifier may occupy.

\subsection{The Nominal Restriction: Universals and Numerals}

In DP, almost modifiers normally require either a universal quantifier (Carlson 1981, Kadmon and Landman 1993) or a numeral (Partee 1986):

a. Almost/nearly/practically every chiropractor plays the ukulele.

b. Almost/nearly/practically all chiropractors play the ukulele.

c. Almost/nearly/practically twenty chiropractors play the ukulele.
a. \#Almost/nearly/practically a/some/the chiropractor plays the ukulele.
b. \#Almost/nearly/practically some/several/many chiropractors play the ukulele.

Negative determiners are of course possible as well, presumably a reflection of the same fact:
a. Almost/nearly/practically no chiropractor plays the ukulele.
b. Almost/nearly/practically none of the chiropractors plays the ukulele.

With measure nouns, though, existential quantifiers are possible: almost a pound of cheese. Likewise, determiners otherwise incompatible with almost-modifiers are legal in the presence of the adjectives entire and whole, which apparently suffice to satisfy the requirement of universal quantification: almost the entire book.

\subsection{The Adjectival Restriction: Non-Gradable Adjectives}

In AP, almost modifiers are odd with gradable adjectives (Hitzeman 1992): ${ }^{2}$ 
(7) a. Herbert is almost/nearly/practically dead.

b. a(n) almost/nearly/practically defunct restaurant
a. \#Herbert is almost/nearly/practically tall.
b. \#a(n) almost/nearly/practically popular restaurant

The gradable adjectives in (8) may occur with these modifiers only to the extent that they can be coerced into non-gradable interpretations. For example, $(8 a)$ is well-formed only to the extent that one can conceive of tall as a clear-cut, discrete predicate that partitions its domain into the clearly tall and the clearly non-tall.

As might be expected, though, an AP whose degree argument is saturated through comparative morphology or an overt measure phrase may occur with an almost modifier:

(9) a. Herbert is almost/nearly/practically taller than Clyde.

b. Herbert is almost/nearly/practically six feet tall.

\subsection{The Verbal Restriction: A Telicity Effect}

In VP, there is a contrast between the effect of almost modifiers on telic and atelic eventualities:

(10) a. Clyde almost/nearly/practically ran into a shopping cart.

b. Clyde almost/nearly/practically died.

c. Clyde almost/nearly/practically reached the top.

(11) a. (\#)Clyde almost/nearly/practically ran around.

b. (\#)Clyde almost/nearly/practically slept.

c. (\#)Clyde almos $1 /$ nearly/practically knew the answer.

An interpretation ${ }^{3}$ in which the event is claimed not to have culminated is possible only with VPs denoting telic eventualities, as in (10). With atelic eventualities, as in (11), no such interpretation is normally possible. It may perhaps be coerced, but only to the extent that the eventuality in question can be coerced into a telic reading. (None of this is to deny, of course, that there are other interpretations possible for (11).)

\subsection{The Adverbial Restriction: Non-Gradability Again, Universality Again}

In adverbial categories, restrictions similar to those already noted reemerge. Almost modifiers may occur in AdvP under roughly the same circumstances as in $\mathrm{AP}$ - gradable de-adjectival adverbs are odd: 
(12) a. The candidate behaved almost/nearly/practically inexcusably.

b. \#The candidate behaved almost/nearly/practically strangely.

As with adjectives, a non-gradable interpretation must be coerced to salvage a sentence like (12b).

The similarity is not to AP alone, however. With quantificational adverbs a universality requirement analogous to that imposed in DPs manifests itself:

a. Chiropractors can almost/nearly/practically always play the ukulele.

b. \#Chiropractors can almost/nearly/practically often/usually/sometimes play the ukulele.

So, as with their determiner counterparts, almost modifiers require universality of quantificational adverbs.

Somewhat more mysteriously, almost modifiers cannot modify adverbs of certain classes, including speaker-oriented and domain adverbs:

a. *Almost/nearly/practically frankly/honestly/truthfully, Greta can play the ukulele.

b. *Almost/nearly/practically legally/officially/anatomically, Clyde is a chimpanzee.

Indeed, almost modifiers seem best compatible with manner and quantificational adverbs.

The now-familiar restrictions arise in PP as well. One way to understand the contrast in (15) is as a kind of universality restriction:

(15) Floyd learned Portuguese almost/nearly/practically without/*with assistance.

Without may involve universal quantification over its object. ${ }^{4}$ With, however, likely does not involve universal quantification.

\subsection{A Glance Outside English}

It does not appear to be a quirk of English that words meaning 'almost' have a cross-categorial distribution and occupy a left-peripheral position. This is the case in a number of languages:

(16) German

(Rapp and Stechow 1999)

a. Fast alle Pflanzen waren vertrocknet. almost all plants were dry

b. Alle Pflanzen waren fast vertrocknet. all plants were almost dry 
c. weil David seinen Hasen fast erwürgte because David his rabbit almost strangled

Polish (vetted by Ania Eubowicz, p.c.)

a. Prawie/niemal każda roślina jest sucha. almost every plant is dry

b. Każda roślina jest prawie/niemal sucha. every plant is almost dry

c. David prawie/?niemal zadusił jego królika. David almost strangled his rabbit

(18) Hebrew

a. kim?at kol cemax hu yaveš almost every plant HU dry 'Almost every plant is dry.'

b. ha-ramzor kim?at yarok the-traffic.light almost green 'The traffic light is almost green.'

c. dani kim?at lo tiken et ha-mexonit ha-zot (Uri Strauss, p.c.) 'Danny almost didn't fix this car.'

(Sevi 1998)

(Sevi 1998)

(19) St'át'imcets (Lillooet Salish)

(Lisa Matthewson, p.c.)

a. tqilh t'u7 tákem i ts'í7a qi-7-cw almost PART all PL.DET deer-DET scared.away(inch)

'Almost all the deer left.'

b. tqilh t'u7 áolsem k Mary almost PART sick DET Mary 'Mary almost got sick'

c. tqilh t'u7 kúkwpi7 k Mary almost PART chief DET Mary 'Mary almost became a chief.'

Naturally, none of this is evidence that the semantics of the various expressions glossed here as 'almost' is invariant across these languages - in fact, it is not. ${ }^{5}$ But it is evidence that the cross-categoriality and left-peripherality of English almost modifiers reflects a more general phenomenon.

\subsection{Summary}

Almost modifiers constitute a natural class distinguished by position and interpretation, whose members may occur in left peripheral positions across a 
range of syntactic categories. In all these categories, they impose intuitively similar semantic restrictions.

\section{Some Analytical Possibilities}

\subsection{Lexical Decomposition}

The various interpretations almost gives rise to have been a central argument for lexical decomposition of verbs (McCawley 1972, recently Rapp and Stechow 1999). Although this debate is of course directly relevant to the analysis of almost generally, it appears to be largely independent of the questions immediately at hand here, and no new evidence will be brought to bear on it, so it will be noted only briefly.

Both McCawley and Rapp and Stechow take (20) to be three-ways ambiguous:

(20) John almost killed Harry.

Each of the three interpretations is slightly more gruesome than the next. On one interpretation, John is claimed to have almost done something. This would be how (20) is interpreted if it reports, for example, a circumstance in which John got extraordinarily angry at Harry, but resisted acting on his rage. On another interpretation, John is claimed to have actually done something which almost caused Harry's death. This would be the interpretation involved in reporting a circumstance in which John shot at Harry, missing him narrowly. On the third interpretation, John is claimed to have actually caused Harry to be almost dead. This would be the interpretation involved in reporting an instance in which John attacked Harry and wounded him seriously.

Notably, the entire class of almost modifiers has this range of interpretations:

(21) John nearly/practically/virtually killed Hamy.

Thus irrespective of whether these interpretations involve ambiguity or vagueness, they, like the distribution and selectional restriction facts noted above, are not a peculiarity of almost.

In a McCawley-style lexical decomposition theory, these effects can be understood as the consequence of whether almost takes scope over various elements of the decomposed verb. Rapp and Stechow approach almost (and its German counterpart fast) from this perspective, implementing lexical decomposition as in (22):

John almost killed Harry.

a. John almost did something: $\operatorname{almost}(w)\left(\lambda w \exists e\left[\operatorname{AGENT}_{\text {ew }}(\mathrm{John}) \wedge \operatorname{BECOME}_{\text {ew }}\left(\lambda w \lambda\right.\right.\right.$ s.DEAD $D_{\text {sw }}($ Harry $\left.\left.\left.)\right)\right]\right)$ 
b. John did something, and it almost caused Harry's death: $\exists e\left[\operatorname{AGENT}_{\text {ew }}(J o h n) \wedge \operatorname{almost}(w)\left(\lambda w . \operatorname{BECOME}_{\text {ew }}\left(\lambda w \lambda s . \operatorname{DEAD}_{\text {sw }}(\right.\right.\right.$ Harry $\left.\left.\left.)\right)\right)\right]$

c. John did something, and it caused Harry to be almost dead: $\exists \mathrm{e}\left[\mathrm{AGENT}_{\mathrm{ew}}(\mathrm{John}) \wedge \mathrm{BECOME}_{\mathrm{ew}}(\lambda \mathrm{w} \lambda \mathrm{s}\right.$. $\operatorname{almost}(\mathrm{w})(\lambda \mathrm{w}$. $\operatorname{DEAD}_{\text {sw }}($ Harry $\left.\left.\left.)\right)\right)\right]$

These different interpretations are derived in this account on the basis of the relative scope of almost, the existential quantifier, and the BECOME predicate. Since for Rapp and Stechow, this semantic decomposition mirrors a decomposition in the syntax, these scope possibilities correlate with syntactic positions occupied by almost (or fast). This permits an account of correlations between the position of fast and the interpretations available.

A core virtue of such an approach is that there is a single almost with a single denotation - for Rapp and Stechow, a modifier of propositions. Variation in the interpretation arises entirely from its position.

Moreover, the telicity effect can be explained in these terms. If the interpretations of almost depend on its scope relative to various predicates in the decomposition, the absence of one of these predicates would reduce the number of possible scope possibilities and hence the number of interpretations. Since the BECOME predicate is absent in the representation of atelic eventualities, one interpretation of almost should be missing in these cases. This amounts to exactly the selectional restiction noted above - the 'almost-culminated' reading is possible only with telic eventualities.

\subsection{Intensional Similarity}

Decomposition on its own, however, is not intended as a theory of what almost means, so much as a theory of why its meaning may vary. A theory of the essential meaning of almost is required independently.

The decomposition account of Rapp and Stechow builds on the denotation for almost in (23), though this is similar to denotations proposed in nondecompositional accounts as well (Sadock 1981, Sevi 1998): ${ }^{6}$

(23) $\operatorname{almost}(w)(p)=1$ iff there is a world w' which is almost not different from $\mathrm{w}$ and $\mathrm{p}\left(\mathrm{w}^{\prime}\right)=1$ and $\mathrm{p}(\mathrm{w})=0$

This is appropriate in a lexical decomposition theory for VP almost (which is what Rapp and Stechow chiefly concern themselves with), but it does not extend straight-forwardly to DP almost.

First, (23) would have to be adjusted - through a type shift, say - so that almost can apply to generalized quantifiers, to yield (24): ${ }^{7}$

$$
\operatorname{almost}_{2}=\lambda \mathrm{w} \lambda \mathrm{Q}_{<<e, s t>, s t>} \lambda \mathrm{P}_{<e, s t>} . \operatorname{almost}(\mathrm{w})(\mathrm{Q}(\mathrm{P})(\mathrm{w}))
$$

This leads to a problem, however. It predicts that (25a) should be assigned an 
interpretation like (25b):

a. Almost every plant is dry.

b. almost $_{2}(\mathrm{w})(\llbracket$ every plant $\rrbracket)(\llbracket$ is dry $\rrbracket)=$ $\operatorname{almost}(\mathrm{w})(\llbracket$ every plant $\rrbracket(\llbracket i$ is dry $\rrbracket)(\mathrm{w}))=$ $\operatorname{almost}(\mathrm{w})(\forall \mathrm{x}[\mathrm{plant}(\mathrm{x})(\mathrm{w}) \rightarrow \operatorname{dry}(\mathrm{x})(\mathrm{w})])$

That is, $(25 \mathrm{a})$ is predicted to mean 'it is almost the case that every plant is dry'. In a situation in which every plant is only minimally moist but no plant is dry, (24a) would be predicted to be true. This is not a possible reading.

Sevi (1998) proposes a denotation for almost like that in (23), but in which almost may, depending on context, operate on not just worlds but also intervals or standards of precision. This additional elaboration would not on its own help here, since what is required is a reduction rather than an increase in the multiplicity of possible interpretations.

\subsection{Exceptives}

If the problem in (25) is due to attempting to extend an account of VP almost to other uses, perhaps it could be avoided by taking an account of DP almost as a starting point instead.

There are apparently no worked-out accounts of DP almost, but von Fintel $(1993,1994)$ mentions in an analysis of exceptive constructions that it may be possible to understand almost in these terms. In other words, perhaps (26a) is analogous to (26b):

a. Almost every plant is dry.

b. Every plant except for a few is dry.

Von Fintel notes that certain exceptive constructions - English but phrases actually impose a universality restriction on quantifiers rather like the one imposed by almost:

Every/*some student but John attended the meeting.

Maybe, then, if DP almost can be understood as a kind of exceptive, other incarnations of almost may as well. Thus, perhaps (28a) is analogous to (28b):

a. The plant is almost dry.

b. The plant is dry, $\left\{\begin{array}{l}\text { except for a few drops } \\ \text { except for some residual moisture } \\ \text { except for the topmost leaves }\end{array}\right\}$.

In other words, one might suppose that almost allows a kind of fudging of the requirements a predicate would normally impose analogous to the kind of 
exceptions it permits in DP. A notion of exceptions may be developed that extends to properties: an exception to $d r y$, for example, would be any property that an individual must have to be dry but in fact lacks. ${ }^{8}$ Almost would require that there be few such exceptions.

There is something appealingly simple and intuitively satisfying about such an approach, and (26-28) can be taken as evidence that there is something to the analogy that lies at its core. And certainly, some general notion of exceptions or counterexamples plays an important role in everyday reasoning. But this approach presents some substantial difficulties that are not easily resolved, and that might be avoided while preserving some of its advantages by taking a slightly different route.

The central problem involves the requirement that these exceptions be few. If exceptions may be properties, this would require counting properties. Counting properties, though, is trouble: Is having three wet leaves a single exception, three exceptions, or both?

One natural solution is to suppose the context of utterance provides a way of structuring the requirements a predicate imposes - for example, in a particular context a particular set of properties may count as the components of being dry. This may permit talk about properties being (proportionally) few to be sensible, but it requires making very deep commitments about what context does.

\subsection{Slack Regulation}

Building on the intuition that almost modifiers involve relaxation of truth conditions, one might imagine assimilating them to other expressions that may be said to have this effect. Lasersohn (1999) identifies a class of expressions he calls 'slack regulators', which includes exactly, more or less, perfectly, and all. These 'serve as signals of the intended degree of approximation to the ruth'. But almost modifiers do not appear to be of this class, for several reasons.

First, slack regulators are not typically cross-categorial in the way almost modifiers are. Although there are slack regulators for various different categories, different slack regulators are specialized for different categories. Exactly and perfectly are apparently restricted to $\mathrm{AP}$, all is restricted to $\mathrm{DP}$ (setting aside its floated form), and more or less is apparently relatively unrestricted. This contrasts sharply with almost modifiers, which are quite homogeneous with respect to the range of categories they may modify.

Second, slack regulators do not systematically impose consistent selectional restrictions in the way almost modifiers do. Every almost modifier imposes the same restrictions, but the restrictions imposed by slack regulators vary. Exactly and perfectly, for example, differ in their compatibility with numerals: exactly thirty chiropractors is possible, but not *perfectly thirty chiropractors.

Third, and probably most significant, slack regulators do not in general give rise to the inference that the sentence they occur in would be false if they were absent: 
(29) a. More or less thirty chiropractors play the ukulele. does not entail

b. It is not the case that thirty chiropractors play the ukulele.

(30) a. Clyde's head is perfectly spherical. does not entail

b. Clyde's head is not spherical.

Yet this is an important property of almost modifiers:

a. Almost thirty chiropractors play the ukulele. does entail

b. It's not the case that thirty chiropractors play the ukulele.

There is some controversy about whether this is in fact an entailment (Sevi 1998, Rapp and Stechow 1999) or an implicature (Sadock 1981, Atlas 1984). But whatever its status, this inference is a signature characteristic of almost modifiers. It would be hard to understand in terms of slack regulation. ${ }^{9}$

\section{Intensional Similarity, and Building Toward Cross-Categoriality}

Each of the analytical possibilities considered so far presents certain problems. This section will attempt to resolve the principal problem confronting the most straight-forward extension of the intensional similarity approach, and consider some ways in which this may lead to an understanding of the restrictions almost modifiers impose.

\subsection{An Initial Word about Intensional Similarity}

The intensional approaches to almost involve asserting that there exists a world in which a proposition is true that is close or similar to the evaluation world (in the case of Rapp and Stechow 1999, 'almost not different' from it). It is, of course, ultimately important exactly what is meant by these closeness relations. For current purposes, though, this issue will be sidestepped as in (32), an initial stab at the denotation of the AP incarnation of almost:

$$
\begin{aligned}
& \text { AP almost: } \\
& \llbracket \text { almost }_{\mathrm{AP}} \rrbracket=\lambda \mathrm{P} \lambda \mathrm{x} \lambda \mathrm{w} . \neg \mathrm{P}(\mathrm{x})(\mathrm{w}) \wedge \exists \mathrm{w}^{\prime}\left[\mathrm{P}(\mathrm{x})\left(\mathrm{w}^{\prime}\right) \wedge \operatorname{CLOSE}(\mathrm{w})\left(\mathrm{w}^{\prime}\right) \wedge\right. \\
& \forall \mathrm{w}^{\prime}\left[\left[\left[\mathrm{w}^{\prime} \leq_{\mathrm{w}} \mathrm{w}^{\prime} \wedge \mathrm{P}(\mathrm{x})\left(\mathrm{w},{ }^{\prime}\right)\right] \rightarrow \mathrm{w}^{\prime}{ }^{\prime}{ }_{\mathrm{w}} \mathrm{w}^{\prime}\right]\right]
\end{aligned}
$$

What this requires is that a proposition be false in the evaluation and true in some close world, and that there be no closer world in which it is true. The closeness relation between worlds here is CLOSE. A notion of comparative closeness 
between worlds is also put to use here: $\mathrm{w}^{\prime} \mathrm{S}_{\mathrm{w}} \mathrm{w}^{\prime \prime}$ ( $\mathrm{w}^{\prime}$ is at least as close to $\mathrm{w}$ as $\mathrm{w}^{\prime}$ ' is) iff all the propositions true both in w and in w' are also true in w' (cf. Lewis 1981). Presumably, CLOSE and comparative closeness are not unrelated. The requirement that only maximally close worlds of the right sort be considered is not crucial at this point, but will prove useful later in defining almost modifiers like nowhere near, so it is included here for consistency of exposition.

\subsection{Trying to Fix the Problem with Almost Every Plant}

The problem noted above with simply extending a propositional analysis of almost to DP is that it would falsely predict that (32a) could mean (32b):

a. Almost every plant is dry.

b. Every plant is almost dry.

A denotation like (34) for DP almost would yield sentence denotations like (35):

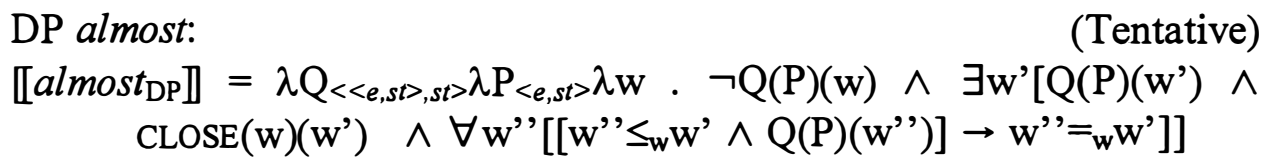

$$
\begin{aligned}
& \llbracket \text { Almost every plant is dry }=\lambda \mathrm{w} . \neg \forall \mathrm{x}[\operatorname{plant}(\mathrm{x})(\mathrm{w}) \rightarrow \operatorname{dry}(\mathrm{x})(\mathrm{w})] \wedge \\
& \exists \mathrm{w}^{\prime}\left[\forall \mathrm{x}\left[\operatorname{plant}(\mathrm{x})\left(\mathrm{w}^{\prime}\right) \rightarrow \operatorname{dry}(\mathrm{x})\left(\mathrm{w}^{\prime}\right)\right] \wedge \operatorname{CLOSE}(\mathrm{w})\left(\mathrm{w}^{\prime}\right) \wedge\right. \\
& \left.\forall w^{\prime \prime}\left[\left[w^{\prime \prime} \leq_{w} w^{\prime} \wedge \forall x\left[\operatorname{plant}(x)\left(w^{\prime}\right) \rightarrow \operatorname{dry}(x)\left(w^{\prime \prime}\right)\right]\right] \rightarrow w^{\prime \prime}={ }_{w} w^{\prime}\right]\right]
\end{aligned}
$$

What (35) requires is that not every plant be dry in the evaluation world, and there be a world among the closest in which every plant is dry that is close to the evaluation world.

The source of the difficulty reflected in (33), then, is that the evaluation world and the close world to which it is being compared may vary not only in what proportion of plants are dry but also in which plants are dry, or indeed in whether any are. In other words, the worlds may vary not in how closely the evaluation world approximates universality of dryness, but also in how closely the evaluation world approximates total or actual dryness.

This can be fixed by simply imposing a requirement that the worlds not vary with respect to the extension of dry. Thus in (36), a requirement is added that only the DP denotation may vary between the compared worlds:

$$
\begin{aligned}
& \text { DP almost: } \\
& \begin{array}{r}
\text { almost } t_{\mathrm{DP}} \rrbracket=\lambda \mathrm{Q}_{<<e, s t>s t>} \lambda \mathrm{P}_{<e, s t>} \lambda \mathrm{w} . \neg \mathrm{Q}(\mathrm{P})(\mathrm{w}) \wedge \exists \mathrm{w}^{\prime}\left[\mathrm{Q}(\mathrm{P})\left(\mathrm{w}^{\prime}\right) \wedge\right. \\
\lambda \mathrm{x}[\mathrm{P}(\mathrm{x})(\mathrm{w})]=\lambda \mathrm{x}[\mathrm{P}(\mathrm{x})(\mathrm{w},)] \wedge \operatorname{cLOSE}(\mathrm{w})\left(\mathrm{w}^{\prime}\right) \wedge \forall \mathrm{w}^{\prime},\left[\left[\mathrm{w}^{\prime \prime} \mathrm{s}_{\mathrm{w}} \mathrm{w}^{\prime} \wedge\right.\right. \\
\left.\left.\left.\mathrm{Q}(\mathrm{P})\left(\mathrm{w}^{\prime \prime}\right)\right] \rightarrow \mathrm{w}^{\prime \prime}={ }_{\mathrm{w}} \mathrm{w}^{\prime}\right]\right]
\end{array}
\end{aligned}
$$

Since this enforces identity of dry things between worlds, the problem in (33) will not arise. The desired reading, however, can still be attained by varying the 
quantity of plants among worlds. With this adjustment, almost every plant is dry would receive an interpretation roughly like 'if there were slightly fewer plants, every plant would be dry'.

\subsection{The Universality Restriction}

The denotation in (34) may account for the incompatibility of almost with existentially quantifying determiners.

A sentence such as (37a) will receive the interpretation in (37b):

$$
\begin{aligned}
& \text { a. \#Almost a/some plant is dry. } \\
& \text { b. } \lambda w \text {. } \neg \exists x[\operatorname{plant}(x)(w) \wedge \operatorname{dry}(x)(w)] \wedge \exists w^{\prime}\left[\exists x \left[\operatorname{plant}(x)\left(w^{\prime}\right) \wedge\right.\right. \\
& \left.\operatorname{dry}(x)\left(w^{\prime}\right)\right] \wedge \lambda y[\operatorname{dry}(y)(w)]=\lambda y\left[\operatorname{dry}(y)\left(w^{\prime}\right)\right] \wedge \operatorname{CLOSE}(w)\left(w^{\prime}\right) \wedge \\
& \left.\left.\left.\forall \mathrm{x}\left[\operatorname{plant}(\mathrm{x})\left(\mathrm{w}^{\prime}\right) \rightarrow \operatorname{dry}(\mathrm{x})\left(\mathrm{w}^{\prime \prime}\right)\right]\right] \rightarrow \mathrm{w}^{\prime \prime}={ }_{\mathrm{w}} \mathrm{w}^{\prime}\right]\right]
\end{aligned}
$$

What (37b) requires is that there be no dry plants in the evaluation world, and that something in the evaluation world that is dry but not a plant be a plant in a world that is not very distant.

This, however, is an exceptionally strange thing to say. Certainly, it does not amount to saying something like 'it is almost the case that a plant is dry'. To the extent that one can access intuitions about what sentences such as (37a) might mean - which is not great - it seems to me that they can indeed mean this, though it is fiendishly difficult to imagine a context in which one might want to express such a thing. The strangeness of existentially-quantifying determiners with almost, then, may follow from this pragmatic strangeness.

DPs with numerals - almost thirty plants - will thus be ruled out on the parse in which almost modifies the DP. But the alternative structure in which almost modifies thirty, a non-gradable adjective, will not be ruled out, just as the almost dead plants would not be.

\subsection{The Telicity Effect}

This sort of semantics may explain the impossibility of 'almost-culminated' interpretations with atelic eventualities. Since in all worlds, atelic eventualities by definition end but do not culminate, it will never be the case that there exists a world in which a particular atelic eventuality culminated. Yet this is exactly what this interpretation of almost would require:

$$
\begin{aligned}
& \text { VP almost: } \\
& \llbracket \text { almost } \mathrm{vP}_{\mathrm{P}} \rrbracket=\lambda \mathrm{P} \lambda \mathrm{e} \lambda \mathrm{w} . \neg \mathrm{P}(\mathrm{e})(\mathrm{w}) \wedge \exists \mathrm{w}^{\prime}\left[\mathrm{P}(\mathrm{e})\left(\mathrm{w}^{\prime}\right) \wedge \operatorname{cLOSE}(\mathrm{w})\left(\mathrm{w}^{\prime}\right) \wedge\right. \\
& \left.\forall \mathrm{w}^{\prime \prime}\left[\left[\mathrm{w}^{\prime \prime} \leq_{\mathrm{w}} \mathrm{w}^{\prime} \wedge \mathrm{P}(\mathrm{e})\left(\mathrm{w}, \mathrm{w}^{\prime}\right)\right] \rightarrow \mathrm{w}^{\prime \prime}={ }_{\mathrm{w}} \mathrm{w}^{\prime}\right]\right] \\
& \llbracket \text { Clyde }_{1} \text { almost slept } t_{1} \rrbracket=\lambda \mathrm{P} \lambda \mathrm{e} \lambda \mathrm{w} \cdot \neg \operatorname{slept}(\text { Clyde })(\mathrm{e})(\mathrm{w}) \wedge \\
& \exists w^{\prime}\left[\operatorname { s l e p t } ( \operatorname { C l y d e } ) ( e ) ( w ^ { \prime } ) \wedge \operatorname { C L O S E } ( w ) ( w ^ { \prime } ) \wedge \forall w ^ { \prime } \left[\left[w^{\prime}{ }^{\prime} \leq_{w} w^{\prime} \wedge\right.\right.\right.
\end{aligned}
$$




$$
\left.\left.\left.\operatorname{slept}(\text { Clyde })(e)\left(w^{\prime \prime}\right)\right] \rightarrow w^{\prime \prime}={ }_{w} w^{\prime}\right]\right]
$$

It is perfectly possible for (39) to be true, but it can never be true by virtue of Clyde's sleep having culminated in some close world.

\subsection{The Non-Gradability Restriction}

At first gloss, denotations such as those proposed above may appear to account for the strangeness of gradable adjectives with almost. Given what has been suggested so far, AP almost requires that an adjective clearly not hold of an individual in the evaluation world and clearly hold in a maximally close world. To determine which worlds are maximally close, it is necessary to know, for every world, whether in that world the adjective holds of the individual. For a gradable adjective, such a determination would seem impossible. In the case of \#Clyde is almost tall, for example, as we consider worlds in which Clyde's height gradually increases, we would need to know exactly when we have reached a world in which Clyde counts as tall. To do this, it would be necessary to identify with absolute precision the particular height an individual must attain to be tall and fail to attain to be not tall. Unmodified tall does not permit this.

But, in fact, typical assumptions about gradable adjectives make this explanation unavailable. A usual view is that gradable adjectives relate an individual and a degree (Seuren 1973, Cresswell 1976, and many others since; discussion and further references in Kennedy 1997). In the absence of overt degree phrases, the degree argument is a standard value provided by context. Once the degree argument position has been saturated, gradable adjectives become indistinguishable from non-gradable adjectives. By the time almost encounters an AP denotation, then, the distinction between gradable and nongradable adjectives has been rendered invisible.

In (40), for example, if the contextually-supplied standard degree of height is six feet, (40a) will be interpreted along the same lines as (40b):
a. Clyde is tall.
b. Clyde is six feet tall.

With respect to almost modifiers, though, there is a stark difference:
a. ?Clyde is almost/nearly/practically tall.
b. Clyde is almost/nearly/practically six feet tall.

If both of these sentences simply involve saturation of a degree argument, this contrast is unexpected. The almost modifier in both cases would apply to the property of individuals that are at least six feet tall.

It is possible to conceive of circumstances, however unusual, in which (41a) would be less strange, apparently by virtue of being coerced into an interpretation like (41b). An organization of tall people - say, one devoted to 
political advocacy for extended legroom in cars - may require that its members be at least six feet tall. In discussing Clyde's potential membership, one might felicitously utter (41a). But it is exactly this precise identification of a standard degree of height that renders this context unusual. If such a precisely identified standard degree were provided by any context in which a gradable adjective is used without degree modification, it would not be necessary to consider unusual contexts such as this, nor indeed would such contexts seem especially unusual. It seems reasonable, then, to regard the view that all contexts provide precise standards according to which unmodified gradable adjectives may be interpreted as an idealization.

The almost facts run afoul of this idealization. Perhaps, then, what is required to explain the contrast in (41) is not a more refined semantics for almost, but rather an understanding of the semantics of standard degrees that might better permit distinguishing different means of saturating the degree argument position. $^{10}$

\section{Final Steps toward Cross-Categoriality: Another Kind of Decomposition}

Denotations have now been proposed for almost in a number of categories, but these remain distinct denotations, and nothing has been proposed for other almost modifiers. This section sets out some syntactic assumptions motivated by the distribution of almost modifiers that make possible an account of the crosscategoriality of the class.

\subsection{Type Shifting?}

Before other possibilities are considered, though, it is sensible to first ask whether the necessary cross-categoriality can be achieved through type shifting (e.g. Partee 1987). This would seem a rather rocky road to travel, though.

One reason for skepticism is conceptual. The necessary type shift would be from modifiers of properties to modifiers of generalized quantifiers (or, alternatively, vice versa). There is no reason to doubt that this type shift should be possible in principle. But it would, at least, be quite unusual. It is not obvious that there is any independent evidence for such a type shift. So before embracing this option too enthusiastically, it would seem prudent to find some other area of the grammar where such a type shift might prove useful.

There is an empirical difficulty as well, which has already been noted in section 2. Variation in the interpretation of almost modifiers across categories is not in type alone. As suggested in 3.2, DP almost modifiers impose an additional requirement that property-modifying ones do not. So the requisite type shift would have to do more than shift types - it would have to impose or suspend this requirement as well. This would be an operation significantly more complex than a mere type shift. 


\subsection{Distribution}

The chief syntactic property of almost modifiers, as noted above, is that for every category they modify, they occur in a high, left-peripheral position: (repeating (3))

(42) a. [Almost/nearly/practically every chiropractor] plays the ukulele.

b. Tilden [almost/nearly/practically won].

c. The soup is [almost/nearly/practically free of insects].

d. Floyd sailed [almost/nearly/practically around the world].

e. The candidate behaved [almost/nearly/practically inexcusably].

To find that modifiers with a particular kind of semantics occur in a particular range of syntactic positions is not surprising, of course.

At least in this instance, it may be sensible to take this as a fundamentally syntactic fact in need of a syntactic solution. A semantic explanation of exactly this distribution would be nice, and maybe even more satisfying, but it is not obvious where it would come from. Certainly, there is nothing in the semantics proposed so far that would favor a distribution high in the extended projection, much less on the left periphery. The positions in which almost modifiers occur may plausibly be a syntactic natural class, but they do not appear to be a semantic one. It might in principle have been the case, for example, that all propertydenoting expressions could license almost modification. But not so - nouns and NPs (in the Abney 1987 sense) clearly do not: *an almost/nearly/practically gorilla, *an almost/nearly/practically bottle.

A syntactic explanation, however, is eminently available, in the language of modifier-licensing features Cinque (1999) provides. To account for a wide variety of distributional facts involving a large number of adverb classes across a large number of languages, he proposes that different classes of adverbs occur as specifiers to distinct functional projections in fixed syntactic positions, where they check a licensing feature. Perhaps, then, almost modifiers are licensed in this general fashion, by checking a feature - here dubbed [+ALMOST] - in a fixed position in functional structure:

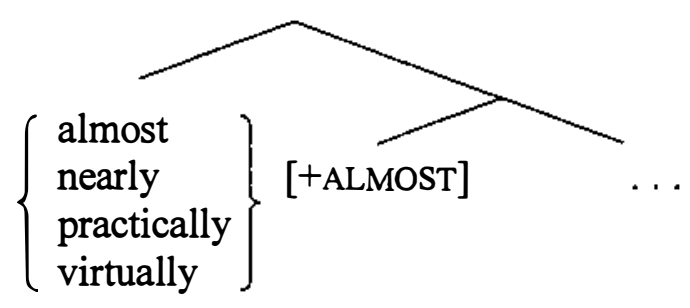

Whether a separate functional projection, as (43) reflects, is really required or this feature can be bundled with others in some other projection will not be explored further here, though I will assume the former here for simplicity. ${ }^{11}$

The distribution of almost modifiers can therefore follow from the fixed 
position of their licensing feature in the functional structure of the categories in which it occurs. That almost modifiers are obligatorily phrase-peripheral would follow from supposing that this fixed position is high in the extended projection of each category. That almost modifiers obligatorily occupy leftward positions would follow from assuming, in the Cinque style, that they occupy specifier positions.

\subsection{A Division of Labor}

As noted in section 2.1, almost has been witness to a great deal of lexical decomposition. It will now be made the victim of some.

With the introduction of this licensing feature in functional structure, the semantics of almost modifiers can now be divided into two parts. Most of the work can be assigned to the licensing features themselves:

$$
\begin{aligned}
& \text { a. }\left[\left[{ }^{+A L M O S T} T_{D P}\right] \rrbracket=\lambda Q \lambda R \lambda P \lambda w . \neg Q(P)(w) \wedge \exists w^{\prime}\left[Q(P)\left(w^{\prime}\right) \wedge\right.\right. \\
& \lambda \mathrm{x}[\mathrm{P}(\mathrm{x})(\mathrm{w})]=\lambda \mathrm{x}\left[\mathrm{P}(\mathrm{x})\left(\mathrm{w}^{\prime}\right)\right] \wedge \mathrm{R}(\mathrm{w})\left(\mathrm{w}^{\prime}\right) \wedge \forall \mathrm{w}^{\prime}{ }^{\prime}\left[\left[\mathrm{w}^{\prime}{ }^{\prime} \mathrm{s}_{\mathrm{w}} \mathrm{w}^{\prime} \wedge\right.\right. \\
& \left.\mathrm{Q}(\mathrm{P})\left(\mathrm{w} \text { ')] } \rightarrow \mathrm{w}^{\prime \prime}={ }_{\mathrm{w}} \mathrm{w}^{\prime}\right]\right] \\
& \text { b. }\left[{ }^{+} \text {ALMOST }_{A P}\right] \rrbracket=\lambda P \lambda R \lambda x \lambda w . \neg P(x)(w) \wedge \exists w^{\prime}\left[\mathrm{P}(\mathrm{x})\left(\mathrm{w}^{\prime}\right) \wedge\right. \\
& \left.\mathrm{R}(\mathrm{w})(\mathrm{w}) \wedge \forall \mathrm{w}^{\prime \prime}\left[\left[\mathrm{w}^{\prime \prime} \leq_{\mathrm{w}} \mathrm{w}^{\prime} \wedge \mathrm{P}(\mathrm{x})(\mathrm{w},)\right] \rightarrow \mathrm{w}^{\prime \prime}={ }_{\mathrm{w}} \mathrm{w}^{\prime}\right]\right] \\
& \text { c. [[+ALMOSTV]] }=\lambda \mathrm{P} \lambda \mathrm{R} \lambda \mathrm{e} \lambda \mathrm{w} . \neg \mathrm{P}(\mathrm{e})(\mathrm{w}) \wedge \exists \mathrm{w}^{\prime}\left[\mathrm{P}(\mathrm{e})\left(\mathrm{w}^{\prime}\right) \wedge\right. \\
& \left.\mathrm{R}(\mathrm{w})\left(\mathrm{w}^{\prime}\right) \wedge \forall \mathrm{w}^{\prime \prime}\left[\left[\mathrm{w}^{\prime \prime} \leq_{\mathrm{w}} \mathrm{w}^{\prime} \wedge \mathrm{P}(\mathrm{x})\left(\mathrm{w}^{\prime \prime}\right)\right] \rightarrow \mathrm{w}^{\prime \prime}={ }_{\mathrm{w}} \mathrm{w}^{\prime}\right]\right]
\end{aligned}
$$

Here, licensing features take a modified expression and an almost modifier as arguments. All the almost modifiers themselves need to do is provide various values for the intensional closeness relation $\mathrm{R}$. For example:

$$
\llbracket \text { almost } \rrbracket=\lambda \mathrm{w} \lambda \mathrm{w}^{\prime} \cdot \operatorname{cLOSE}(\mathrm{w})\left(\mathrm{w}^{\prime}\right)
$$

This allows almost modifiers themselves to have entirely uniform denotations across categories. On this approach, it is not necessary to assume that every almost modifier has distinct homophonous forms for each category it can modify. It is still necessary, though, to suppose that there are several incarnations of the [+ALMOST] licensing feature.

But this may not be so shocking. Certainly, there are many independently attested correlations in functional structure across categories. Degree-related projections, for example, occur both in $\mathrm{AP}$ and AdvP, and indeed it is not even entirely clear to what extent these categories are distinct. The relation between nominal and verbal projections, moreover, is famously close. So perhaps assuming different flavors of this feature, while less than maximally elegant, may be necessary for a principled reason - and considerably more elegant than reproducing this categorial multiplicity independently for every almost modifier.

This approach, then, captures the correlation between the position and interpretation of the almost class through a division of labor, wherein part of the semantic burden is borne by the almost modifier itself, and part by its structural 
position through licensing features in fixed positions in functional structure. ${ }^{12}$

\subsection{How Do Almost Modifiers Vary?}

The major differences among almost modifiers can now be understood as variation in the intensional closeness relation provided:

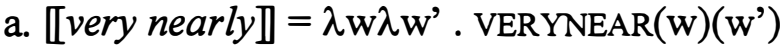
b. 【nearly $\rrbracket=\lambda \mathrm{w} \lambda \mathrm{w}^{\prime}$. $\mathrm{NEAR}(\mathrm{w})\left(\mathrm{w}^{\prime}\right)$
c. 【nowhere near $\rrbracket=\lambda w \lambda w^{\prime}$. $\operatorname{FAR}(w)\left(w^{\prime}\right)$

Thus very near provides a relation of greater proximity between worlds than nearly, and nowhere near provides a relation of distance. Since these relations will ultimately be used to compare the evaluation world to the closest worlds in which a proposition holds, a sentence containing nowhere near will require the closest worlds in which the proposition holds to be far:

$$
\begin{aligned}
& \text { a. Herbert is [nowhere near [[+ALMOST } \left.\mathrm{AP}_{\mathrm{AP}}\right] \text { dead]]. } \\
& \text { b. } \llbracket\left[+{ }^{A L M O S T} \mathrm{AP}_{\mathrm{AP}}\right] \rrbracket(\llbracket \text { dead } \rrbracket)(\llbracket \text { nowhere near } \rrbracket)(\llbracket \text { Herbert } \rrbracket)=\lambda \mathrm{w} \text {. } \\
& \neg \text { dead(Herbert)(w) } \wedge \exists \mathrm{w}^{\prime}\left[\operatorname{dead}(\operatorname{Herbert})\left(\mathrm{w}^{\prime}\right) \wedge \operatorname{FAR}(\mathrm{w})\left(\mathrm{w}^{\prime}\right) \wedge\right. \\
& \left.\forall w^{\prime \prime}\left[\left[w^{\prime \prime} \leq_{w} w^{\prime} \wedge \operatorname{dead}(\operatorname{Herbert})\left(w^{\prime \prime}\right)\right] \rightarrow w^{\prime \prime}={ }_{w} w^{\prime}\right]\right]
\end{aligned}
$$

Because of the requirement that only maximally close worlds be considered, it is not necessary to independently encode into the semantics that, in addition to there being a distant world in which Herbert is dead, there must also not be any close ones in which he is.

Like a number of other almost modifiers, nowhere near appears to consist of two prosodic words, but like other members of the class, it is not internally compositional or syntactically complex. Even very nearly, which would otherwise seem likely to be compositional, is frozen - substituting other degree words for very is impossible: *rather nearly every chiropractor; *extremely nearly every chiropractor. Likewise, just about is an almost modifier, but not bare about: *(just) about every chiropractor; * (just) about around the world. ${ }^{13}$

Apart from the intensional closeness relation provided, almost modifiers may also vary in register, as between the casual damn near and the formal virtually. ${ }^{14}$

\section{Concluding Remarks}

One quite intuitive notion that this sort of approach does not reflect, perhaps to its detriment, is that almost modifiers involve, in some sense that would have to be made precise, points on a scale (cf. Hitzeman 1992). Naturally, this is not in principle incompatible with the intensional approach taken here - one may imagine constructing scales by ranking worlds in a particular way. Indeed, the 
closeness relations among worlds may be a step in this direction. Another intriguing possibility is comparing not worlds, but focus alternatives (Maribel Romero, p.c.). These possibilities will have to be left unexplored here.

To summarize, the empirical aim of this paper has been to establish that almost modifiers constitute a natural class - they share a cross-categorial distribution, occur in the same position in each category, give rise to the same range of readings, and impose similar restrictions on the categories they modify. Because of this, the behavior of almost cannot be understood as a mere idiosyncrasy. Headway toward explaining the properties of almost modifiers may be made by combining a semantics rooted in intensional similarity with a model of modification in which semantic labor is divided between modifiers and the syntactic features in functional structure that license them.

\section{Endnotes}

* Thanks to Barbara Partee, Lisa Matthewson, Angelika Kratzer, Ana Arregui, Meredith Landman, Ania Łubowicz, Ora Matushansky, and Uri Strauss, and to many people at SALT XI for numerous helpful comments and suggestions, not nearly enough of which I have been able to reflect here.

1 Three almost modifiers are taken to be representative here and subsequently, but similar facts hold for the whole class.

2 Sevi (1998) argues that this is not quite the case - he finds almost happy relatively normal. This may, however, be a difference in how easily various normally gradable adjectives can be coerced into nongradable interpretations.

3 I use 'interpretation' as a term neutral with respect to whether this is ambiguity or vagueness.

$4 \quad$ Say, in this case taking the form of quantification over pieces or instances of assistance: $\forall \mathrm{x}$ [assistance $(\mathrm{x}) \rightarrow \neg$ Floyd learned to speak Portuguese with $\mathrm{x}$ ].

$5 \quad$ Rapp and Stechow (1999), for example, discuss some differences between German fast and English almost.

6 This is altered from Rapp and Stechow's original in some purely notational ways.

7 This assumes that almost applies to a DP rather than a D, but this is not crucial - a similar argument could be made from the alternative assumption.

$8 \quad$ More generally, and a bit more precisely: $C$ is an exception to $A(B)$ iff $\square[\mathrm{A}(\mathrm{B}) \rightarrow \mathrm{C}(\mathrm{B})] \wedge \neg \mathrm{C}(\mathrm{B})$.

9 Despite all these empirical differences, though, the conceptual machinery Lasersohn suggests for these expressions - 'pragmatic halos' - bears a certain intuitive resemblance to what may be required for almost modifiers. Moreover, at least some apparent slack-regulators - absolutely and positively - bear a greater resemblance than others to almost modifiers. Absolutely and positively occur apparently quite cross-categorially and always left-peripherally, like almost modifiers, and may even impose some similar selectional restrictions. Horn (1972) notes that absolutely in DP may be restricted to universal quantifiers, a 
property which positively seems to share.

10 It does not seem clear to me whether supervaluation approaches to adjective semantics (e.g. Kamp 1975) might be better equipped to avoid this sort of difficulty. Interpreting \#almost tall in such a framework, given what has been said here, would not seem any more problematic than interpreting almost deadboth would simply involve identifying the closest worlds in which Clyde is in the positive extension of the adjective. Another approach entirely to the problem would be to relate the contrast in (41) to the possibility that the almost modifier in (41b) modifies the measure phrase alone: [almost six] feet tall (Karina Wilkinson, p.c.). A difficulty with such an approach, though, is that one would not want to suppose that only measure phrases, and not adjectives themselves, may have almost modifiers - this would rule out almost dead. Moreover, if six is itself a non-gradable adjective as assumed here, it would not be possible to rule out almost modification of adjectives without also ruling out almost modification of numerals and hence of this measure phrase.

11 If evidence that might help decide this question turns out to be lacking, it may be preferable to assume the bundling approach rather than a distinct projection. The semantics that will be proposed momentarily to interpret the structure in (43) would extend to this alternative conception as well, provided that function composition is permitted below the $\mathrm{X}^{0}$ level. On such a view, the licensing feature [+ALMOST] would be interpreted by function-composing with the other features it is bundled with.

12 This approach to modification may be useful in otherwise unrelated areas of the grammar, including certain adverbs and DP adverbials (Morzycki 2001).

13 An interesting case in this respect is not quite and quite. These both appear to be almost modifiers, but the latter appears to be a negative polarity item: $I$ *(don't) think quite everyone has left yet. (The degree word quite - quite tall, quite upset - is another beast entirely, and is not a negative polarity item.)

14 Sadock (1981) suggests another possible difference. Not quite and almost, he claims, differ in that not quite entails that the proposition it applies to is false, while almost merely gives rise to this inference as an implicature. Hitzeman (1992) argues against this.

\section{References}

Atlas, Jay David. 1984. 'Comparative Adjectives and Adverbials of Degree: An Introduction to Radically Radical Pragmatics'. Linguistics and Philosophy 7.

Carlson, Greg. 1981. 'Distribution of Free-Choice Any'. Proceedings, CLS 17.

Cinque, Guglielmo. 1999. Adverbs and Functional Heads: A Cross-Linguistic Perspective. Oxford University Press, New York.

Cresswell, M.J. 1976. 'The Semantics of Degree'. In Barbara Partee, ed. Montague Grammar. Academic Press: New York.

von Fintel, Kai. 1993. 'Exceptive Constructions'. Natural Language Semantics 1, 
123-148.

von Fintel, Kai. 1994. 'Restrictions on Quantifier Domains'. Ph.D. dissertation, University of Massachusetts Amherst.

Hitzeman, Janet. 1992. 'The Selectional Properties and Entailments of Almost'. Proceedings of the Chicago Linguistics Society 28.

Horn, Laurence R. 1972. On the Semantic Properties of Logical Operators in English. Ph.D. dissertation, UCLA.

Kadmon, Nirit and Fred Landman. 1993. 'Any'. Linguistics and Philosophy 16.

Kamp, Hans. 1975. 'Two Theories about Adjectives'. In E. Keenan, ed. Formal Semantics of Natural Language. Cambridge University Press, Cambridge.

Kennedy, Christopher. 1997. Projecting the Adjective: The Syntax and Semantics of Gradability and Comparison. Ph.D. dissertation, UC Santa Cruz.

Lasersohn, Peter. 1999. 'Pragmatic Halos'. Language 75.

Lewis, David. 1981. 'Ordering Semantics and a Precise Semantics for Counterfactuals'. Journal of Philoso phical Logic 10, 217-234.

McCawley, James D. 1972. 'Kac and Shibtani on the Grammar of Killing'. J. Kimbal, ed., Syntax and Semantics 1, 139-49. Academic Press, New York.

Morgan, Jerry. 1969. 'On Arguing About Semantics'. Papers in Linguistics 1, 49-70.

Morzycki, Marcin. 2001. 'Interpreting DP Adverbials'. Proceedings of WCCFL 20. Cascadilla Publications, Somerville, Mass.

Partee, Barbara H. 1986. 'Any, Almost, and Superlatives' ('The Airport Squib'). University of Massachusetts Amherst ms.

Partee, Barbara H. 1987. 'Noun Phrase Interpretation and Type-Shifting Principles'. In J. Groenendijk, D. de Jongh, and M. Stokhof, eds. Studies in Discourse Representation Theory and the Theory of Generalized Quantifiers. Foris, Dordrecht.

Rapp, Irene and Amim von Stechow. 1999. "Fast "Almost" and the Visibility Parameter for D-Adverbs'. Journal of Semantics 16.

Sadock, Jerrold. 1981. 'Almost'. In Peter Cole, ed. Radical Pragmatics. Academic Press, New York.

Sevi, Aldo. 1998. 'A Semantics for Almost and Barely'. Masters thesis, Tel-Aviv University.

Seuren, Pieter A.M. 1973. 'The Comparative'. In Ferenc Kiefer and Nicolas Ruwet, eds. Generative Grammar in Europe. Reidel, Dordrecht.

Department of Linguistics

South College

University of Massachusetts

Amherst, MA 01003 USA

morzycki@linguist.umass.edu 